\title{
EL PRIMER FRACASO DEL INI \\ EN ASTURIAS: SIASA (1942-1971)
}

PAZ BENITO DEL POZO

\section{LA POLITICA INDUSTRIAL NACIONAL QUE ENMARCA A S.I.A.S.A.}

En los años de vigencia del régimen franquista, la política económica del país estuvo presidida por una obsesión: la industrialización. Al finalizar la guerra civil, la economía española estaba gravada por un capital humano mermado y un capital material de difícil recuperación. La escasez y pobreza generalizadas sirvicron de argumento para concebir y llevar a cabo una política económica fundada en la idea de que la renta por habitante y la productividad eran más altas en la industria que en cualquier otro sector de la producción. En consecuencia, se impuso la tendencia a potenciar las actividades industriales, dejando en segundo plano a las de tipo agrario, hasta entonces definitorias de nuestra economía.

Para lograr el objetivo de industrialización a ultranza y superar así el estancamiento y conseguir un crecimiento rápido evitando la dependencia exterior (considerada en esta época como un factor indeseable), se adoptó una estrategia de sustitución de importaciones, también llamada de autarquía económica. En relación con esto, a partir de 1938 tomó cuerpo una política industrial intervencionista que hacía hincapié en la necesidad de supeditar la iniciativa privada a los intereses nacionales y en el papel vigilante del Estado con respecto a la industria. Los instrumentos principales de los que se sirvió dicha política fueron la Ley de Ordenación y Defensa de la Industria Nacional, de 1939, y el Instituto Nacional de Industria (INI), fundado en 1942 para hacer posible la intervención directa del Estado en la producción industrial a través de sociedades anónimas por él fundadas o participadas en diversa proporción.

Desde el punto de vista sectorial, se potenciaron las actividades industriales generadoras de bienes de producción o de equipo, además de la industria minera. Ello obedecía a la idea de que una potente industria transformadora requicre para su desarrollo de la existencia previa de industrias "básicas", tales como la siderurgia, la química pesada o la energía eléc- 
trica y la producción de carbón. La industria nacional debía empeñarse, pues, en la producción de las materias primas consumidas por las actividades transformadoras, hacia cuyo crecimiento se orientan en última instancia los esfuerzos de los planificadores económicos. Autarquía económica e industrialización acelerada del país trataron, pues, de compaginarse recurriendo a la producción de materias básicas de bajo coste y mediocre calidad que posibilitasen, a su vez, la expansión de las industrias transformadoras, reduciendo al mínimo las importaciones.

\section{LA IMPORTANCIA DE SIASA PARA AVILES}

La sociedad anónima titulada "Siderúrgica Asturiana, S. A." se constituyó en Madrid mediante escritura fechada en 9 de diciembre de 1942. Su objeto social era llevar a cabo el beneficio de minerales pobres de hierro con alto contenido en sílice según un conocido procedimiento alemán. Tal producto no era otra cosa que un sustitutivo de la chatarra en procesos siderúrgicos, materia de la cual estaba muy necesitado el país por falta de una producción propia suficiente para atender a la industria siderúrgica en expansión y por las dificultades para importar la misma, habida cuenta de la política autárquica que se impuso desde 1939 y que se prolongaría hasta 1959.

La única factoría de la empresa se ubicó en la ría de Avilés, por dos razones: de un lado, por la proximidad a los yacimientos de mineral (hierro) y combustible (carbón); de otro, por la existencia de un puerto comunicado por tren con el interior del país, es decir, conectado con el mercado de consumo potencial (este tipo de factores de localización está presente en las estrategias de la mayoría de las industrias establecidas en Asturias antes y después de la época que nos ocupa, lo que se explica, en parte, por la especialización sectorial de los proyectos industriales que arraigan en la región desde los orígenes de su industrialización).

En el momento de producirse la llegada de SIASA a la ría avilesina, ésta contaba tan sólo con una empresa industrial importante: la "Real Compañía Asturiana de Minas", de capital belga y dedicada a la producción de zinc metal, ácido sulfúrico y superfosfatos, con factorías en Arnao y San Juan de Nieva. Asimismo, ningún establecimiento siderúrgico se hallaba en la zona, lo que convertía a SIASA en la primera empresa de tal naturaleza radicada en Avilés y en la segunda factoría de envergadura con asiento en la ría (recordemos que la instalación de los primeros astilleros se produce a partir de 1943, caso de "Aniceto Fernández Hevia", "Morán Quirós y Cía.", "Iglesias y Martínez" y "La Naval Asturiana”; que la primera fábrica de ENDASA no llega hasta 1949, y que ENSIDESA no figura hasta 1952). 
Asimismo, puede afirmarse que SIASA inaugura una nueva etapa en el proceso de industrialización de Avilés, de signo expansivo y con la característica de tener como protagonista a la industria de bienes de equipo, la misma que recibe el máximo apoyo dentro del programa de "reconstrucción nacional». Dicha etapa abarca desde los primeros años del decenio de 1940 (después de un período de atonía industrial prolongado más de veinte años) hasta 1952, esto es, coincidiendo con la llegada de ENSIDESA, que, a su vez, marca el comienzo de la fase de crecimiento súbito e intenso de la actividad industrial avilesina.

\section{EL PROYECTO INDUSTRIAL DE LA EMPRESA}

SIASA centró su actividad en una producción de bajos costes y altos rendimientos inmediatos propiciados por la política de sustitución de importaciones: la chatarra sintética. Con este nombre se designa a los nódulos de hierro obtenidos a partir de minerales muy siliciosos de baja ley de hierro como son los asturianos (inapropiados para el beneficio en alto horno), según el procedimiento alemán Renn-Krupp. Para la reducción del mineral se empleaban menudos de antracita y hulla, materia de escasa aplicación en la siderurgia. El sistema aplicado permitía, de un lado, revalorizar un mineral carente de interés industrial por resultar antieconómico su beneficio; de otro lado, prescindir de combustible de calidad, dando como resultando un producto final apto para horno alto en sustitución de la chatarra y en el horno eléctrico para la fabricación de acero.

Las obras de instalación de la planta, situada en la margen izquierda de la ría, al sur de la dársena de San Juan de Nieva, comenzaron en 1942, pero las dificultades que encontraron sus promotores para adquirir la maquinaria básica (de fábrica extranjera y de compleja introducción en el país, a consecuencia del limitado cupo de las importaciones autorizadas) obligaron a paralizar el proyecto. Su inviabilidad a corto plazo motivó la solicitud de ayuda al Estado, que no puso reparos en apoyar a SIASA en razón del interés estratégico de su producto, un sustitutivo de la chatarra. El amparo estatal se llevó a efecto por dos vías: la declaración de Industria de Interés Nacional (Decreto de 23 de mayo de 1947) y la capitalización con fondos públicos a través del INI. En efecto, entre 1948 y 1950 , el INI participó una ampliación del capital de la empresa que ascendió a cuarenta millones de pesetas, llegando a representar su aportación económica el 31 por 100 del capital social de SIASA.

Ello hizo posible, aunque con once años de retraso sobre la fecha de constitución de la empresa, que SIASA pusiera en marcha las instalaciones avilesinas (la inauguración oficial aconteció el 23 de agosto de 1955, con 
asistencia del entonces Jefe del Estado, el general Franco, que llegó a Avilés a bordo del yate "Azor" y aprovechó la visita para inspeccionar las obras de ENSIDESA, en la margen opuesta de la ría).

En esencia, la fábrica de chatarra se componía de un horno horizontal rotatorio de 60 metros de longitud y 3,60 metros de diámetro, con una capacidad de producción de 30.000 toneladas anuales. El sistema RennKrupp aplicado permitía, como se ha dicho más arriba, obtener nódulos de hierro aptos para alto horno (tipo Martin-Siemens) en sustitución de chatarra o en el horno eléctrico para la fabricación de acero.

Las campañas de trabajo, de duración normal de noventa días, finalizaban con el agotamiento de la vida del refractario del horno, y para su reposición, así como para las reparaciones mecánicas y eléctricas de la planta, eran necesarios treinta días de parada, siendo, por tanto, 265 días al año los de fabricación efectiva. La producción diaria media en campaña completa ascendía a unas 115 toneladas de nódulos, resultando una producción anual de 30.000 toneladas, aproximadamente. Por lo que respecta a la plantilla de trabajadores, ésta se elevaba a 160 personas, repartidas entre la fábrica y las oficinas.

En 1953, SIASA contaba con un mercado muy necesitado de chatarra y, por ello, apropiado para la salida del producto que fabricaba, aceptado a pesar de su baja calidad. Al establecerse en 1961 un nuevo precio de venta para su producción (el precio del nódulo bajó de 2.600 a 2.500 pesetas la tonelada), la empresa se vio obligada a afrontar un proceso de modernización encaminado a reducir gastos de mantenimiento que acarreó, entre otros cambios, una reducción escalonada de plantilla que afectó a un total de cuarenta personas, es decir, al 25 por 100 del total de la nómina de 1960. Así, de una plantilla integrada por 160 personas se pasa en 1965 a 148, en 1966 a 133, en 1967 a 124 y en 1968 queda fijada en 120 (cuadro I).

\section{CUADRO I}

Volumen y estructura profesional de la plantilla de SIASA

\begin{tabular}{|c|c|c|c|c|}
\hline & 1965 & 1966 & 1967 & 1968 \\
\hline 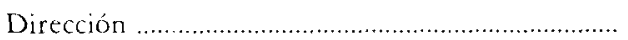 & 3 & 3 & 3 & 3 \\
\hline 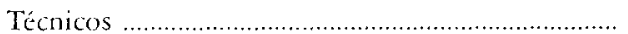 & 26 & 23 & 21 & 13 \\
\hline Administrativos . . & 8 & 7 & 7 & 8 \\
\hline 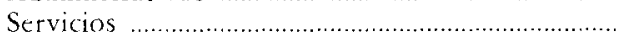 & 13 & 11 & 16 & 17 \\
\hline 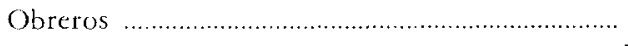 & 98 & 89 & 77 & 79 \\
\hline TOTAL .. & 148 & 133 & 124 & 120 \\
\hline
\end{tabular}

Fuffre: Delegación Provincial de Trabajo de Oviedo, "Expediente de crisis de SIASA", 1968 . 
Al mismo tiempo, se estudió con los técnicos alemanes la posibilidad de que la factoría adaptase sus instalaciones para producir "esponja de hicrro". Entretanto, la evolución de los ejercicios cconómicos de la empresa en el período de 1953-1961 arroja un balance positivo-con la excepción de 1954 , por razones que no vienen al caso-, con valores que oscilan entre el 0,009 y el 2,928 (cuadro II).

\section{CUADRO II}

Evolucion de los ejericios económicos de SIASA (1953-1962)

\begin{tabular}{|c|c|c|c|}
\hline$A \tilde{n}$ & Boneficto & $A \bar{n} \prime$ & Beneficio \\
\hline 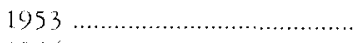 & 0,009 & 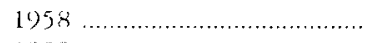 & 2,918 \\
\hline 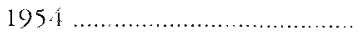 & $--0,180$ & 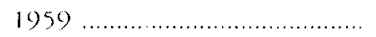 & 1,346 \\
\hline 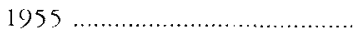 & 0,714 & 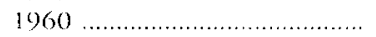 & 0,648 \\
\hline 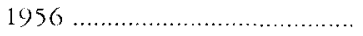 & 2,212 & 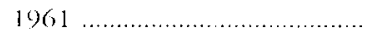 & 1,283 \\
\hline 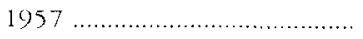 & 2,741 & $1962 \ldots \ldots \ldots \ldots$ & 1,861 \\
\hline
\end{tabular}

Fuente: Delegación Provincial de Trabajo de Ovicdo, "lixpediente de crisis de SIASAm, 1968.

\section{LOS FUNDAMEN'TOS DE LA CRISIS}

Si hasta 1961 la chatarra sintética salida de SIASA no tuvo dificultades para ser absorbida por el necesicado mercado siderúrgico nacional, a partir de ese año un hecho fue decisivo en el cambio de signo del negocio que tratamos: el INI decide oricntar la política acerera nacional hacia el consumo de mineral de hicrro, tanto espanol como extranjero. Tal determinación, sumada a la política de precios (caída progresiva del precio de la chatarra sintética y aumento paralelo del correspondiente a los factores de producción) y la apertura del mercado español, desencadenó la crisis irreversible de SIASA, volcada en un negocio a todas luces coyuntural. Prucba de ello es la negativa evolución de los ejercicios económicos desde 1963 (sólo pérdidas y ninguna ganancia) y la desaparición de la cartera de clientes, la cual quedó reducida a un solo comprador: ENSIDESA. A este respecto hay que añadir que ENSIDESA compraba los hicros de SIASA bajo presiones del INI, interesado en mantener a flote a esta última.

Aparte de las medidas de salvamento antes señaladas (modernización de las instalaciones, reducción de gastos y ajustes de plantilla), la Dirección de la empresa diseñó un plan de reconversión consistente cn montar una ace- 
ría que complementase la planta Renn-Krupp con el afino de los nódulos. Esta idea, surgida en 1964, movió a SIASA a solicitar la inclusión en el régimen de Acción Concertada, demanda que fue denegada por el Ministerio de Industria por considerar que el proyecto no se ajustaba a los fines perseguidos por el Programa Siderúrgico Nacional. Seguidamente, en 1965, la empresa inició una prospección de mercados para estudiar la posible aceptación del producto "esponja de hierro", al tiempo que la firma "Fried Krupp Industriebau" experimentaba con éxito en la planta de Avilés la fabricación del nuevo producto.

Pero el principal escollo, la financiación de las inversiones necesarias, no se resolvió al fracasar la empresa en todos sus intentos por captar apoyos y colaboraciones de grupos ajenos a la sociedad. La situación se hizo insostenible para SIASA, que declara en un "Informe" emitido en 1968 haber agotado los recursos económicos para seguir fabricando nódulos, así como tener unas pérdidas acumuladas de casi 36 millones de pesetas. Se impone a partir de ese momento la búsqueda urgente de soluciones.

\section{SOLUCIONES PARA SIASA}

Ante los hechos expuestos, SIASA planteó en enero de 1968 la enajenación del activo fijo y, a través del INI, of reció a ENSIDESA la adquisición de las instalaciones de la planta avilesina. Una comisión técnico-económica de ENSIDESA estudió de inmediato la posible operación, emitiendo un Informe en el cual se aceptaba la opción de compra por un importe total de 56 millones de pesetas. Previa aprobación por el Consejo de Administración de ENSIDESA, la propuesta de compra-venta es elevada al INI, quien, a su vez, ratifica la operación planteada por SIASA.

Simultáneamente, el Consejo de Administración de SIASA solicitó la necesaria autorización del Ministerio de Industria, que contestó en los siguientes términos: "En relación con la propuesta de ampliación de financiamiento de ENSIDESA en 56 millones de pesetas para adquirir el activo fijo de SIASA (...) este Departamento no encuentra justificación suficiente que haga aconsejable la absorción por ENSIDESA de SIASA..." Por su parte, el Ministerio de Hacienda también puso objeciones a la operación. Sólo el Ministerio de Trabajo, movido por el interés de evitar la destrucción de empleos, apoyó la integración de SIASA en ENSIDESA, postura que le colocó del lado del INI y frente a los otros dos ministerios citados.

SIASA, interesada en que el Estado se hiciese cargo de la fábrica y de sus trabajadores, por ser ya un negocio nada rentable y sin expectativas de 
beneficios a la vista de la evolución del mercado desde 1961, urdió la estratagema de solicitar ante la Delegación Provincial de Trabajo el cese de los productores de la empresa, esto es, de tramitar el expediente de crisis, a sabiendas de que éste era un modo eficaz de conseguir la pretendida autorización de Industria, que, sin duda, recibiría todo tipo de presiones procedentes del Ministerio de Trabajo. Incluso la Delegación Provincial de Sindicatos tomó parte en el asunto, asumiendo el papel de mediador entre SIASA y el Ministerio de Industria, al que dirige en septiembre de 1968 un ruego: que reconsidere la resolución sobre SIASA y autorice su enajenación urgente a ENSIDESA. Los argumentos que empleó fueron, en esencia, dos: que la operación estaba en consonancia con la anunciada política de concentración y fusión de empresas del propio Ministerio de Industria y que, al mismo tiempo, vendría recomendada por el deseo del Gobierno de impedir por todos los medios la progresión del paro en España.

Las gestiones de la dirección de SIASA, apoyada por el INI y las diversas instancias de Trabajo - que logran imponer sus criterios--, dieron en pocas semanas los resultados apetecidos: el Ministerio de Industria autorizó, al fin, que los trabajadores de la empresa pasasen a formar parte de la plantilla de ENSIDESA y que ésta adquiriese las acciones de la sociedad. A cambio, SIASA debía suspender la tramitación del expediente de crisis.

\section{DESAPARICION TOTAL DE LA PLANTA DE NODULOS}

En 1971 se consumó la liquidación de la empresa y, con ello, quedó confirmado el fracaso estrepitoso de SIASA, así como de la estrategia del INI en Avilés, mezcla de una operación de salvamento de empresas y búsqueda de instalaciones para el desarrollo de una actividad plancada en función de las necesidades concretas del período de autarquía e industrialización a ultranza.

Con el tiempo habrá de verse que ENSIDESA, al fin y al cabo, no hizo tan mal negocio, pues los 56 millones que le costó SIASA los recuperó con creces a través de dos operaciones: primero, con la venta de las instalaciones de la planta como chatarra; después, en el año 1985, con la venta al Ayuntamiento de Avilés de los terrenos que integraban cl antiguo recinto de la fábrica de nódulos (unos 154.000 metros cuadrados, por los que la Corporación pagó 300 millones de pesetas), destinados a la construcción de un polígono industrial, "Las Arobias", que representa la contribución de Avilés a la ZUR asturiana. 
El caso de SIASA, sin duda singular dentro de la región, es extrapolable a otros proyectos industrialcs llevados a cabo en los años de la postguerra civil, cuya vida efímera c incluso disparatado contenido eran consustanciales al fin para el que nacicron y estaban en consonancia con la política irdustrial que los alumbró.

\section{FUENTES Y BIBLIOGRAFIA}

Areviamento de Aviles: Boletin de Información Municipal, mayo-junio 1987, Avilés.

CAMARA DE COMER(G), INDUSTRIA Y NAVEGACION DE AvilES: Boletin Informatino, julio-agosto de 1955, mayo-junio de 1956 y agosto-septiembre de 1958, Avilés.

Dhlegacion Provincial dof Trahajo DF Oviedo: "Expedicnte de crisis de Siderútgica Asturiana, S. A.», 1968.

JWTA DFL PlikTO Y RIA DF Avilés, Departamento de Concesiones: "Expediente de SIASA".

BHNTO DEL P(O), P. (1900): La organizuitón del espacio industrial en Asturias, Dcp. de Geografia, Universidad de Oviedo (tesis doctoral inédita).

Brañ, J.; BLESA, M., y MOLFRo, J (1984): El Estado y el cambio tecnologico en la industrializacion tátia. México, FCE.

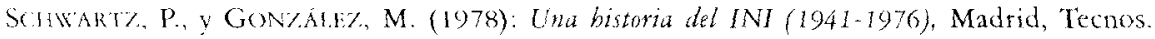

